\title{
Pterostilbene inhibits hepatocellular carcinoma through p53/SOD2/ROS-mediated mitochondrial apoptosis
}

\author{
LIYING GUO $^{1 *}$, KAI TAN $^{2 *}$, HAO WANG $^{3}$ and XUAN ZHANG ${ }^{4}$ \\ ${ }^{1}$ Department of Hepatology, Xi'an No. 8 Hospital, Xi'an, Shaanxi 710061; ${ }^{2}$ Department of General Surgery, Tangdu Hospital, \\ The Fourth Military Medical University, Xi'an, Shaanxi 710038; Departments of ${ }^{3}$ Hematology and \\ ${ }^{4}$ Obstetrics and Gynecology, Xi'an Central Hospital, Xi'an, Shaanxi 710003, P.R. China
}

Received April 13, 2016; Accepted May 27, 2016

DOI: $10.3892 /$ or.2016.5151

\begin{abstract}
Hepatocellular carcinoma (HCC) is one of the most common malignancies and the second cause of cancer-related deaths around the world. Pterostilbene (PTE), is a natural analog of resveratrol, possessing diverse pharmacological activities. In the present study, we aimed to examine the effect of PTE on tumor growth in mouse models of HCC and to elucidate the possible molecular mechanism in vivo and in vitro. We showed that PTE dose-dependently suppressed tumor growth in mice induced by diethylnitrosamine plus carbon tetrachloride, as evidenced by a decrease in the number of tumors and in the maximum size of the tumors. PTE concentration-dependently inhibited cell viability and proliferation in HepG2 cells. PTE increased caspase-3 activities and apoptosis in liver tumor tissues and cells, indicating the activation of the mitochondrial apoptotic pathway. PFT $\alpha$, superoxide dismutase 2 (SOD2) lentivirus and $N$-acetylcysteine (NAC) significantly inhibited PTE-induced inhibition of tumor growth and cell proliferation and increase in apoptosis. PTE dose-dependently increased reactive oxygen species (ROS) levels both in liver tumor tissues and cells, which were inhibited by PFT $\alpha$, SOD2 lentivirus and NAC. PTE resulted in a significant decrease in SOD2 expression in liver tumor tissues and cells, which were inhibited by PFT $\alpha$, but not NAC, indicating that PTE-induced ROS generation was attributed to p53-mediated downregulation of SOD2. Collectively, PTE increased p53 expression, decreased SOD2 expression, and resulted in an increase in the ROS levels and the activation of the mitochondrial apoptotic pathway, leading to inhibition of tumor growth and cell proliferation. These data demonstrated that the p53/SOD2/ROS pathway is critical for PTE-mediated inhibition of tumor growth and HCC cell proliferation.
\end{abstract}

Correspondence to: Professor Xuan Zhang, Department of Obstetrics and Gynecology, Xi'an Central Hospital, 161 Xiwu Road, Xi'an, Shaanxi 710003, P.R. China

E-mail: xuan_zhang11@sina.com

${ }^{*}$ Contributed equally

Key words: pterostilbene, hepatocellular carcinoma, apoptosis, p53, superoxide dismutase 2, reactive oxygen species

\section{Introduction}

Hepatocellular carcinoma (HCC) is the one of the most common malignancies and the second cause of cancer-related deaths worldwide $(1,2)$. More than 600,000 deaths are reported annually (3). In the past few years, early diagnosis and advances in therapeutic measures, such as surgical resection and liver transplantation, have greatly improved the outcome of HCC patients $(4,5)$. However, the general prognosis is still poor with overall survival rates of 3-5\% (6,7). In spite of wellestablished surveillance programs in patients with chronic liver disease, more than $85 \%$ of the cases are diagnosed at an intermediate-advanced stage, which is not suitable for curative management $(8,9)$. In these cases, local surgical resection with chemotherapy is shown to decrease the mortality rate of HCC (10). However, the option of chemotherapy for HCC is limited and drug-resistance occurs in many of the HCC patients. Novel candidate agents for use in chemotherapy for HCC are urgently needed to control the development of HCC.

Pterostilbene (PTE), trans-3,5-dimethoxy-4'-hydroxystilbene, is a natural dimethylated analog of resveratrol. It is reported that PTE possesses diverse pharmacological activities, including antitumor, anti-inflammatory, antioxidant, antiproliferative and analgesic activities (11-13). In recent years, much attention has been given to the antitumor effect of PTE. Feng et al (14) found that PTE is a potent anticancer pharmaceutical against human esophageal cancer. Dhar et al (15) discovered that PTE is a promising natural agent for use as a chemopreventive and therapeutic strategy to curb prostate cancer. PTE derivatives have been found to suppress tumors, such as osteoclastogenesis (16) and colon cancer (17). Moreover, PTE was found to have an inhibitory effect on the growth and invasion of HCC cells $(12,18)$. However, the mechanism involved in the inhibitory effect of PTE on HCC is far from completely understood.

In the present study, we aimed to examine the effect of PTE on tumor growth in mouse models of $\mathrm{HCC}$ and to elucidate the possible molecular mechanism in vivo and in vitro. We showed that PTE dose-dependently suppressed tumor growth in mice induced by diethylnitrosamine (DEN) plus carbon tetrachloride $\left(\mathrm{CCl}_{4}\right)$ and inhibited cell viability and proliferation in vitro. p53-mediated downregulation of superoxide dismutase 2 (SOD2), generation of reactive oxygen 
species (ROS), and the activation of mitochondrial apoptosis were involved in PTE-induced inhibition of tumor growth in vivo and cancer cell proliferation in vitro.

\section{Materials and methods}

Chemicals and reagents. p53 and $\beta$-actin antibodies were obtained from Santa Cruz Biotechnology, Inc. (Santa Cruz, CA, USA). PTE, DEN, $N$-acetylcysteine (NAC), PFT $\alpha$ and most of the chemicals and reagents used in this study were procured from Sigma-Aldrich (St. Louis, MO, USA).

Animal treatment. Animals were treated in accordance with the guidelines approved by the Animal Care and Use Committee of the Fourth Military Medical University (Shaanxi, China). C57 mice were purchased from the Experimental Animal Center of the Fourth Military Medical University. Mice were kept in individual cages with free access to food and water and the environment was at constant temperature and humidity conditions on 12-h light/dark cycles.

Mice were acclimated for 1 week and then randomly divided into 7 groups ( $\mathrm{n}=15)$ : Ctrl, DEN, DEN+PTE $(100 \mathrm{mg} / \mathrm{kg})$, DEN+PTE $(200 \mathrm{mg} / \mathrm{kg})$, DEN+PTE $(200 \mathrm{mg} / \mathrm{kg})+\mathrm{PFT} \alpha$, DEN+PTE $(200 \mathrm{mg} / \mathrm{kg})+\mathrm{LV}-\mathrm{SOD} 2$ and DEN+PTE $(200 \mathrm{mg} / \mathrm{kg})+\mathrm{NAC}$. Mice were injected with DEN plus $\mathrm{CCl}_{4}$ to construct the $\mathrm{HCC}$ model. In brief, mice were intraperitonially injected with DEN $(200 \mathrm{mg} / \mathrm{kg}$, BW) once and 2 weeks later mice were given a $\mathrm{CCl}_{4}(3 \mathrm{ml} / \mathrm{kg})$ injection thrice a week for 6 consecutive weeks. In the groups of DEN+PTE $(100 \mathrm{mg} / \mathrm{kg})$, DEN+PTE $(200 \mathrm{mg} / \mathrm{kg})$, DEN+PTE $(200 \mathrm{mg} / \mathrm{kg})+\mathrm{PFT} \alpha$, DEN+PTE $(200 \mathrm{mg} / \mathrm{kg})+\mathrm{LV}-\mathrm{SOD} 2$ and DEN+PTE $(200 \mathrm{mg} / \mathrm{kg})+\mathrm{NAC}$, mice were intraperitonially injected with PTE (100 or $200 \mathrm{mg} / \mathrm{kg}$ daily) and/or PFT $(10 \mathrm{mg} / \mathrm{kg}$ daily) or SOD2 lentivirus twice (on 2 consecutive days) for 2 weeks throughout the experimental procedure. Mice in the DEN+PTE $(200 \mathrm{mg} / \mathrm{kg})+\mathrm{LV}$-SOD group were treated with $0.4 \times 10^{8} \mathrm{TU}$ LV-SOD2 through an intravenous injection in the tail. Twenty weeks after the injection of DEN, mice were sacrificed after overnight fasting. According to the accepted criteria, the tumors were counted and measured (19). Blood samples were separated and stored for further biochemical determination. A section of the tumor tissue was fixed in $10 \%$ paraformaldehyde for TdT-mediated dUTP nick end labeling (TUNEL) staining. Another section of the tumor tissue was frozen and cut for ROS detection while another area of tumor tissue was homogenized in saline for the determination of caspase activity. The remaining tissues were stored at $-20^{\circ} \mathrm{C}$ for the determination of mRNA and protein expression.

Cell culture and treatment. HepG2 cell lines were purchased from the American Type Culture Collection (ATCC; Manassas, VA, USA). Cells were cultured in Dulbecco's modified Eagle's medium (DMEM) supplemented with fetal bovine serum (FBS; $10 \%), 100 \mathrm{U} / \mathrm{ml}$ penicillin and $100 \mathrm{U} / \mathrm{ml}$ streptomycin. Cells were incubated at $37^{\circ} \mathrm{C}$ in a humidified incubator containing $5 \% \mathrm{CO}_{2}$. For the experimental treatment, cells were incubated with 12.5-100 $\mu \mathrm{M}$ PTE in serum-free medium for $24 \mathrm{~h}$.

Transfection of lentivirus. The scramble or SOD2 lentivirus was transfected into cells to build cells stably expressing SOD2 according to the manufacturer's instructions. Subsequently, cells were treated with $100 \mu \mathrm{M}$ PTE for $24 \mathrm{~h}$.

Cell viability and proliferation. After the treatment, cell viability and proliferation were measured. An MTT assay was conducted to evaluate cell viability. A CCK-8 assay was performed to assess cell proliferation according to the manufacturer's instructions (Sigma-Aldrich). The absorbances at 570 and $450 \mathrm{~nm}$ were measured, respectively. Results are presented as folds of the control.

Biochemical analysis. Serum levels of lactate dehydrogenase (LDH), alanine aminotransferase (ALT), aspartate aminotransferase (AST) and alkaline phosphatase (ALP) were determined using commercial assay kits (Nanjing Jiancheng Bioengineering Institute, Nanjing, China) according to the manufacturer's instructions.

Apoptosis. TUNEL staining was conducted to measure the apoptosis in liver tissues and cells using the In Situ Cell Death Detection kit (Roche Diagnostics, Basel, Switzerland) according to the manufacturer's instructions. The total number of cells and the number of TUNEL-positive stained cells were counted by an independent researcher. At least 6 random fields were counted for each slide. Results are expressed as the percentage of apoptotic cells.

Determination of caspase activity. The activity of caspase-3 in homogenates of liver tissues and cells was determined using commercial assay kits (Beyotime Institute of Biotechnology, Haimen, China) according to the manufacturer's instructions.

ROS determination. The ROS level was detected by DHE, a superoxide sensitive probe. In brief, frozen liver sections and cells were incubated with $10 \mu \mathrm{M} \mathrm{DHE}$ at $37^{\circ} \mathrm{C}$ for $30 \mathrm{~min}$ in the dark. After being washed twice, slides or dishes were observed under a confocal microscope (Olympus, Tokyo, Japan).

Real-time PCR. Total RNA was extracted from the tissue samples and cells using TRIzol reagent according to the manufacturer's instructions (Invitrogen). mRNA (500 ng) was reversely transcribed into cDNA using the First Strand cDNA synthesis kit (Takara Bio, Inc., Otsu, Japan). Target gene expression was quantified by a real-time polymerase chain reaction (PCR) system using SYBR-Green reagents (Takara Bio, Inc.) in a Bio-Rad Cycling Biosystem (Bio-Rad Laboratories, Inc., Hercules, CA, USA). $\beta$-actin was used as an internal control. Amplification conditions were as follows: an initial step at $94^{\circ} \mathrm{C}$ for $5 \mathrm{~min}$, followed by 40 cycles of denaturation at $94^{\circ} \mathrm{C}$ for $30 \mathrm{sec}$, annealing at $63^{\circ} \mathrm{C}$ for $30 \mathrm{sec}$ and then extension at $72^{\circ} \mathrm{C}$ for $10 \mathrm{sec}$. The relative amount of RNA was quantified using the comparative threshold cycle $\left(\mathrm{C}_{t}\right)$ $\left(2^{-\Delta \Delta C t}\right)$ method.

Western blot analysis. Liver tissues and cells were lysed with cell lysis buffer (50 Mm Tris- $\mathrm{HCl}, \mathrm{pH} 8.0,150 \mathrm{mM} \mathrm{NaCl}$, $1 \%$ Triton X-100, 1 mM EDTA, $10 \mathrm{mM} \mathrm{NaF,} 1 \mathrm{mM} \mathrm{Na}_{3} \mathrm{VO}_{4}$, and a protease inhibitor cocktail) on ice for $30 \mathrm{~min}$. After centrifugation at $20,000 \mathrm{x} \mathrm{g}$ for $20 \mathrm{~min}$ at $4^{\circ} \mathrm{C}$, the protein content of the supernatants was determined by BCA assay 
Table I. Effect of PTE on multiplicity, size and incidence of tumors in DEN-treated mice.

\begin{tabular}{lccc}
\hline Groups & No. & Max. size $(\mathrm{mm})$ & Incidence $(\%)$ \\
\hline Ctrl & 0 & 0 & 0 \\
DEN & $18.6 \pm 2.9^{\mathrm{a}}$ & $9.7 \pm 0.8^{\mathrm{a}}$ & 100 \\
DEN+PTE $(100 \mathrm{mg} / \mathrm{kg})$ & $13.2 \pm 2.3^{\mathrm{b}}$ & $5.8 \pm 0.7^{\mathrm{b}}$ & 100 \\
DEN+PTE $(200 \mathrm{mg} / \mathrm{kg})$ & $6.4 \pm 3.7^{\mathrm{b}}$ & $4.0 \pm 0.6^{\mathrm{b}}$ & 100 \\
DEN+PTE $(200 \mathrm{mg} / \mathrm{kg})+\mathrm{PFT} \alpha$ & $12.3 \pm 3.4^{\mathrm{c}}$ & $7.7 \pm 0.9^{\mathrm{c}}$ & 100 \\
DEN+PTE $(200 \mathrm{mg} / \mathrm{kg})+$ SOD2 KU & $10.6 \pm 3.1^{\mathrm{c}}$ & $7.3 \pm 1.1^{\mathrm{c}}$ & 100 \\
DEN+PTE $(200 \mathrm{mg} / \mathrm{kg})+\mathrm{NAC}$ & $11.9 \pm 2.4^{\mathrm{c}}$ & $7.6 \pm 1.4^{\mathrm{c}}$ & 100 \\
\hline
\end{tabular}

Results are presented as the mean \pm SEM. ${ }^{a} \mathrm{p}<0.05$, compared with the Ctrl group; ${ }^{b} \mathrm{p}<0.05$, compared with the DEN group; ${ }^{\mathrm{p}} \mathrm{p}<0.05$, compared with the DEN+PTE (200 mg/kg) group. PTE, pterostilbene; DEN, diethylnitrosamine; SOD2, superoxide dismutase 2; NAC, $N$-acetylcysteine; Ctrl, control. No., indicates the number of tumors; Max. size, indicates the maximum size of the tumors.

Table II. Effect of PTE on the profiles of liver enzymes in the DEN-treated mice.

\begin{tabular}{|c|c|c|c|c|}
\hline Groups & $\mathrm{LDH}(\mathrm{U} / \mathrm{l})$ & $\operatorname{ALT}(\mathrm{U} / \mathrm{l})$ & AST (U/l) & $\operatorname{ALP}(\mathrm{U} / \mathrm{l})$ \\
\hline Ctrl & $132 \pm 10.1$ & $78 \pm 6.9$ & $67 \pm 8.2$ & $114 \pm 10.4$ \\
\hline DEN & $298 \pm 11.2^{\mathrm{a}}$ & $196 \pm 8.5^{\mathrm{a}}$ & $216 \pm 10.3^{\mathrm{a}}$ & $278 \pm 9.5^{\mathrm{a}}$ \\
\hline DEN+PTE (100 mg/kg) & $235 \pm 10.8^{\mathrm{b}}$ & $151 \pm 9.7^{\mathrm{b}}$ & $166 \pm 5.5^{\mathrm{b}}$ & $232 \pm 6.7^{b}$ \\
\hline DEN+PTE $(200$ mg/kg) & $198 \pm 7.8^{\mathrm{b}}$ & $112 \pm 9.4^{\mathrm{b}}$ & $97 \pm 6.8^{b}$ & $169 \pm 8.3^{b}$ \\
\hline DEN+PTE $(200 \mathrm{mg} / \mathrm{kg})+\mathrm{PFT} \alpha$ & $238 \pm 9.1^{\mathrm{c}}$ & $156 \pm 5.9^{c}$ & $167 \pm 9.2^{c}$ & $218 \pm 5.7^{\mathrm{c}}$ \\
\hline DEN+PTE $(200 \mathrm{mg} / \mathrm{kg})+\mathrm{SOD} 2 \mathrm{KU}$ & $242 \pm 8.1^{c}$ & $152 \pm 7.3^{c}$ & $159 \pm 4.8^{c}$ & $229 \pm 10.8^{c}$ \\
\hline DEN+PTE (200 mg/kg)+NAC & $235 \pm 7.8^{c}$ & $149 \pm 6.6^{c}$ & $161 \pm 8.2^{c}$ & $199 \pm 8.4^{\mathrm{c}}$ \\
\hline
\end{tabular}

Results are expressed as the mean \pm SEM. ${ }^{\mathrm{a}} \mathrm{p}<0.05$, compared with the Ctrl group; ${ }^{\mathrm{b}} \mathrm{p}<0.05$, compared with the DEN group; ${ }^{\mathrm{c}} \mathrm{p}<0.05$, compared with the DEN+PTE (200 mg/kg) group. PTE, pterostilbene; DEN, diethylnitrosamine; SOD2, superoxide dismutase 2; NAC, $N$-acetylcysteine; LDH, lactate dehydrogenase; ALT, alanine aminotransferase; AST, aspartate aminotransferase; ALP, alkaline phosphatase; Ctrl, control.

kit (Pierce, Rockford, IL, USA). Subsequently, equal volumes of supernatants and 2X SDS loading buffer were mixed and boiled for $5 \mathrm{~min}$. Samples containing equal amounts of protein were subjected to SDS-PAGE and then transferred onto an $\mathrm{NC}$ membrane. After blocking with non-fat milk for $1 \mathrm{~h}$ at room temperature, the membranes were incubated with indicated primary antibodies overnight at $4^{\circ} \mathrm{C}$. After being washed four times, the membranes were incubated in the appropriate horseradish peroxidase-conjugated secondary antibodies at $37^{\circ} \mathrm{C}$ for $45 \mathrm{~min}$. The protein bands were visualized using chemiluminescent reagents according to the manufacturer's instructions (Thermo Fisher Scientific) and quantified using an image analyzer Quantity One system (Bio-Rad Laboratories, Inc.).

Statistical analysis. Results are expressed as the mean \pm SEM. All the experiments were performed at least 3 times. The results were analyzed using GraphPad Prism software (GraphPad Software, Inc., San Diego, CA, USA) by one-way ANOVA followed by an SNK-q test for multiple comparisons. $\mathrm{P}<0.05$ was considered statistically significant.

\section{Results}

PTE inhibits tumor growth in mice and inhibits proliferation and promotes apoptosis in HepG2 cells. To investigate the effect of PTE on tumor growth, an HCC mouse model was established using $\mathrm{DEN} / \mathrm{CCl}_{4}$ administration. In Table I, we showed that the incidence of tumorigenesis, the number of tumors and the maximum size of the tumors in the DEN-treated mice were $100 \%, 18.6 \pm 2.9$ and $9.7 \pm 0.8 \mathrm{~mm}$, respectively. The administration of PTE did not affect the incidence of tumorigenesis (Table I). However, PTE significantly decreased the number of tumors and the maximum size of the tumors in the DEN-treated mice. The results showed that in the $100 \mathrm{mg} / \mathrm{kg}$ PTE group, the number of tumors and the maximum size of the tumors were reduced to $13.2 \pm 2.3$ and $5.8 \pm 0.7 \mathrm{~mm}$, respectively (Table I). In the $200 \mathrm{mg} / \mathrm{kg}$ PTE group, the number of tumors and the maximum size of the tumors were reduced to $6.4 \pm 3.7$ and $4.0 \pm 0.6 \mathrm{~mm}$, respectively (Table I). In addition, the activities of LDH, ALT, AST and ALP were significantly increased by $\mathrm{DEN} / \mathrm{CCl}_{4}$ treatment which were inhibited by PTE in a dose-dependent manner (Table II). The results indicated that PTE administration protected against tumor growth and liver injury in the DEN-treated mice. Moreover, we examined the effect of PTE on cancer cell proliferation in HepG2 cell lines. Cells were incubated with 12.5-100 $\mu \mathrm{M}$ PTE for $24 \mathrm{~h}$ and then cell viability and proliferation were measured. In Fig. 1A and B, we showed that 25-100 $\mu \mathrm{M}$ PTE concentration-dependently decreased cell viability and proliferation in HepG2 cells. The results indicated that PTE inhibited the proliferation of HCC cells in vitro. 
A
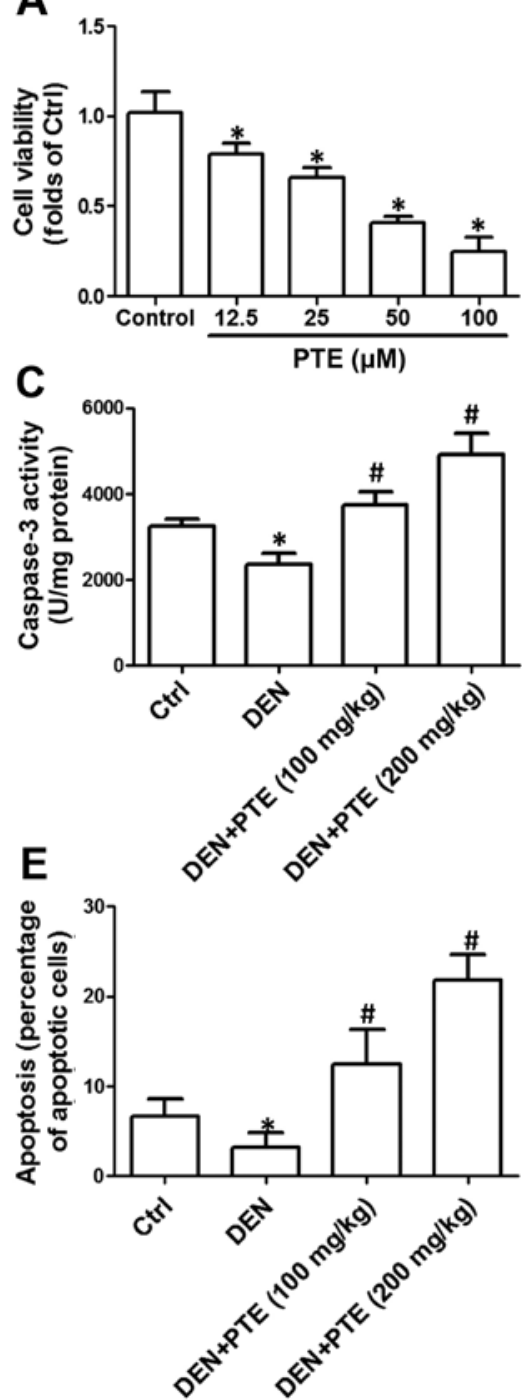

B

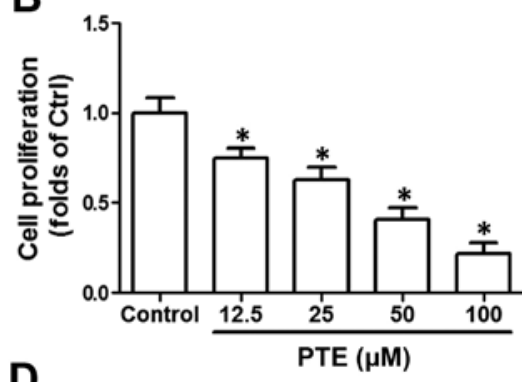

D
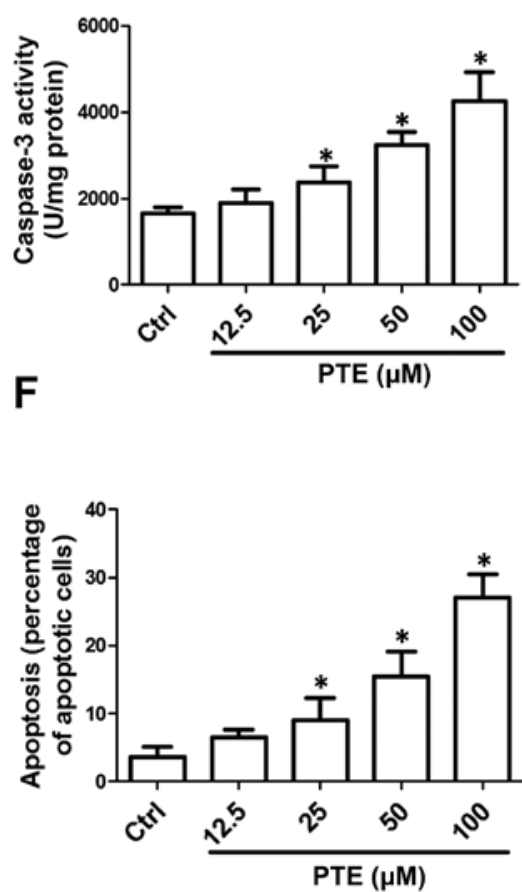

Figure 1. Effect of PTE on cell viability, proliferation and apoptosis. HepG2 cells were incubated with 12.5-100 $\mu$ M PTE for $24 \mathrm{~h}$. Subsequently, (A) cell viability was detected by an MTT assay and (B) cell proliferation was detected with a CCK- 8 kit. DEN plus $\mathrm{CCl}_{4}$-treated mice were injected with the indicated doses of PTE. (C) Caspase-3 activities in liver tumor tissue homogenates and (D) in HepG2 cells were determined by commercial kits. (E) Apoptosis in liver tumor tissue and (F) HepG2 cells was determined by TUNEL assay and the results are presented as the percentage of apoptotic cells. "p $<0.05$, compared with that of the Ctrl. " $\mathrm{p}<0.05$, compared with that of the DEN group. PTE, pterostilbene; DEN, diethylnitrosamine; $\mathrm{CCl}_{4}$, carbon tetrachloride; Ctrl, control.

Furthermore, the effect of PTE on apoptosis in liver tumor tissues and cells was evaluated. As shown in Fig. 1C, the activity of caspase-3 in the DEN-treated mice was significantly increased with PTE administration. In the HepG2 cells, 25-100 $\mu \mathrm{M}$ PTE concentration-dependently increased caspase-3 activity (Fig. 1D). Compared with the DEN group, PTE administration markedly increased the percentage of apoptotic cells (Fig. 1E). PTE $(25-100 \mu \mathrm{M})$ concentration-dependently increased the percentage of apoptotic cells in the HepG2 cells (Fig. 1F). The results indicated that PTE activated the mitochondrial apoptotic pathway and induced significant apoptosis in tumor tissues and cells.

Upregulation of 53 is involved in the PTE-induced inhibitory effect on HCC. In the next step, we examined the possible role of p53 in the inhibitory effect of PTE on HCC. As shown in Fig. 2A, in the DEN-treated mice, PTE administration dose-dependently increased p53 expression. In Fig. 2B, we showed that 50 and $100 \mu \mathrm{M}$ PTE concentration-dependently increased the protein expression of $\mathrm{p} 53$. To elucidate the role of upregulation of the p53 PTE-induced inhibitory effect on HCC in vivo and in vitro, mice and cells were treated with PFT $\alpha$, an inhibitor of p53. The results showed that PFT $\alpha$ significantly inhibited the decrease in the number of tumors and the maximum size of the tumors as well as the LDH, ALT, AST and ALP activities induced by PTE in the DEN-treated mice (Tables I and II). In the presence of PFT $\alpha$, the PTE-induced decrease in cell viability and proliferation in HepG2 cells was significantly suppressed (Fig. 2C and D). Moreover, inhibition of p53 by PFT $\alpha$ suppressed the PTE-induced increase in apoptosis both in mice in vivo and cells in vitro. These results indicated that p53-mediated regulation of apoptosis was involved in the inhibitory effect of PTE on HCC tumor growth in vivo and on cell proliferation in vitro (Fig. $2 \mathrm{E}$ and $\mathrm{F}$ ).

ROS generation mediates the inhibitory effect of PTE on $H C C$. Next, we evaluated whether ROS generation mediated apoptosis induced by PTE in vivo and in vitro. In Fig. 3A, we 
A
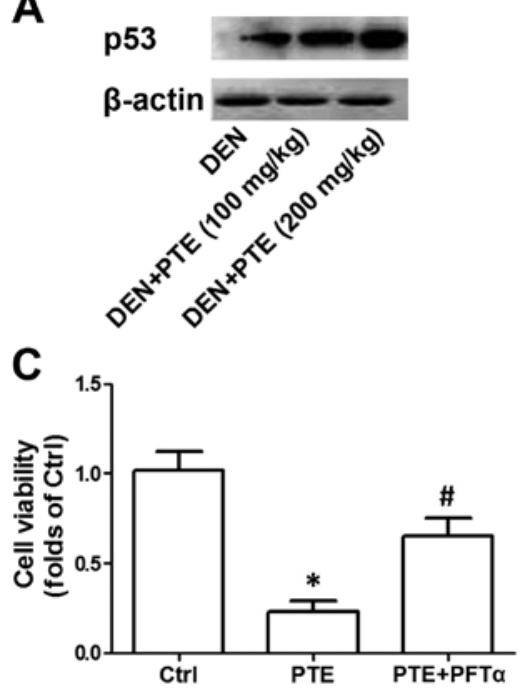

E

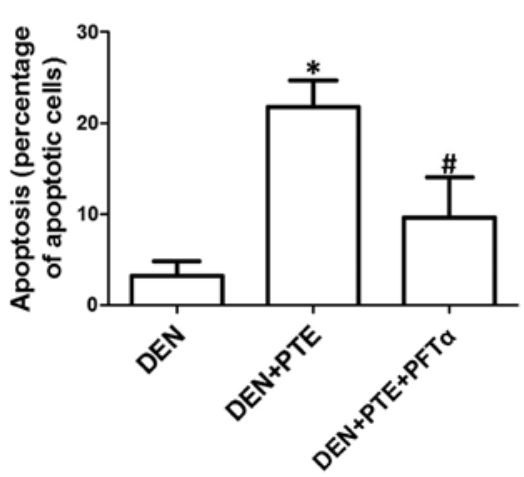

B
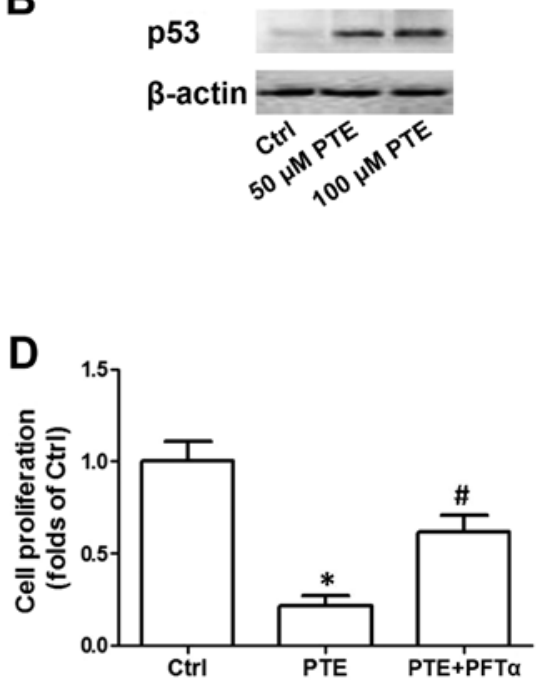

$\mathbf{F}$

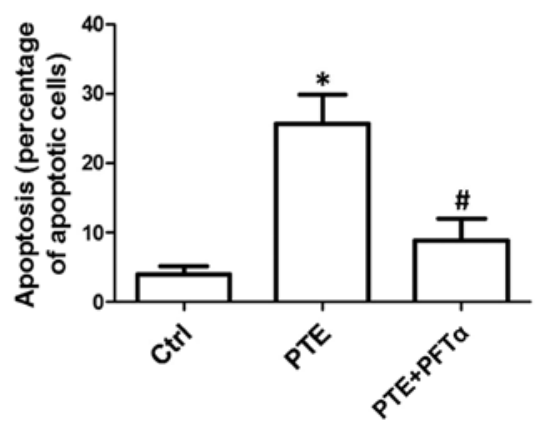

Figure 2. Role of p53 in the effect of PTE on cell viability, proliferation and apoptosis. DEN plus $\mathrm{CCl}_{4}$-treated mice were injected with indicated doses of PTE. HepG2 cells were incubated with the indicated concentrations of PTE for $24 \mathrm{~h}$. (A) Protein expression of p53 in tumor tissues and (B) cells was determined by western blot analysis. HepG2 cells were incubated with $100 \mu \mathrm{M}$ PTE in the presence or absence of $10 \mu \mathrm{M}$ PFT $\alpha$ for 24 h. After that, (C) cell viability was

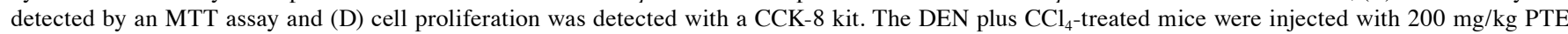
with or without $10 \mathrm{mg} / \mathrm{kg}$ PFT $\alpha$. (E) Apoptosis in liver tumor tissue and (F) HepG2 cells was determined by TUNEL assay and the results are presented as the percentage of apoptotic cells. " $\mathrm{p}<0.05$, compared with that of the Ctrl or DEN. ${ }^{\#} \mathrm{p}<0.05$, compared with that of the PTE group. PTE, pterostilbene; DEN, diethylnitrosamine; $\mathrm{CCl}_{4}$, carbon tetrachloride; $\mathrm{Ctrl}$, control.

showed that PTE significantly increased DHE staining in liver sections, indicating an increase in ROS production. PFT $\alpha$, overexpression of SOD2 by lentivirus infection and NAC, a potent antioxidant, significantly inhibited PTE-induced ROS generation in the tumor tissues (Fig. 3A). Consistently, in the HepG2 cells, PTE resulted in a significant increase in ROS generation which was inhibited by PFT $\alpha$, overexpression of SOD2 by lentivirus infection and NAC (Fig. 3B). Moreover, the role of ROS generation in the effect of PTE on tumor growth, cell proliferation and apoptosis was examined. As shown in Tables I and II, the PTE-induced decrease in the number of tumors and the maximum size of the tumors as well as LDH, ALT, AST and ALP activities were inhibited by LV-SOD2 and NAC. LV-SOD2 and NAC also inhibited the PTE-induced decrease of cell viability and proliferation in the HepG2 cells (Fig. 3C and D). Moreover, the PTE-mediated increase in apoptosis in tumor tissues and cells was inhibited by LV-SOD2 and NAC (Fig. 3E and F). These results indicated that p53-mediated ROS generation was involved in the inhibitory effect of PTE on HCC tumor growth in vivo and on cell proliferation in vitro. p53-mediated inhibition of SOD2 is responsible for the inhibitory effect of PTE on HCC. Considering the important role of SOD2 in counteracting ROS, we evaluated the role of SOD2 in p53-mediated apoptosis induced by PTE. Since overexpression of SOD2 significantly inhibited PTE-induced suppression of tumor growth and cell proliferation, it was indicated that a decrease in SOD2 was involved in tumor growth and cell proliferation in HCC. However, whether the expression of SOD2 was regulated by p53 was unknown. In the next step, we evaluated the expression of SOD2 using real-time PCR. As shown in Fig. 4A and B, in both DEN-treated liver tissues and HepG2 cells, PTE resulted in a significant decrease in SOD2 expression. LV-SOD2 enhanced the expression of SOD2 to a level that was markedly higher than that of the DEN group or control cells (Fig. 4A and B). In the presence of PFT $\alpha$, the PTE-induced decrease in SOD2 was significantly inhibited both in vivo and in vitro (Fig. 4A and B). However, NAC had no significant effect on SOD2 expression, indicating that downregulation of SOD2 was upstream of ROS generation (Fig. 4A and $\mathrm{B}$ ). The results demonstrated that downregulation of SOD2 was a link between upregulation of 

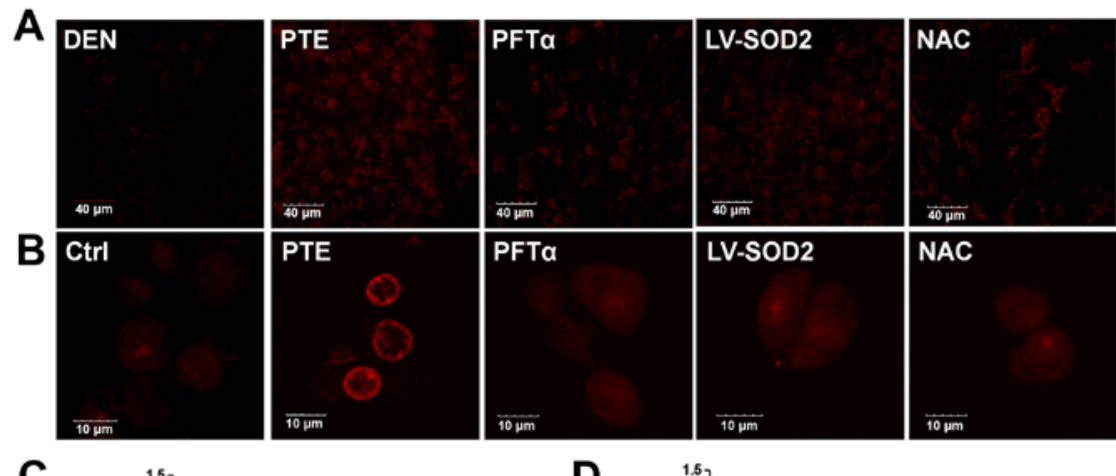

C

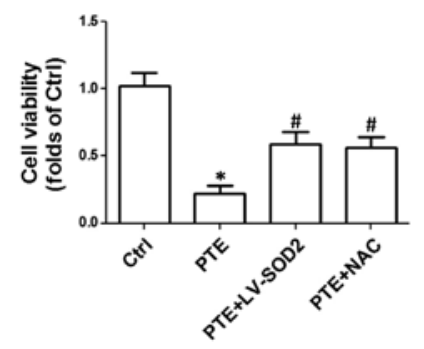

$\mathbf{E}$

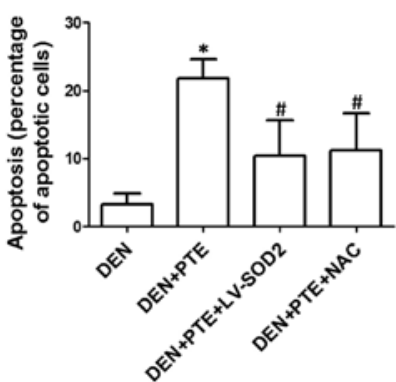

D

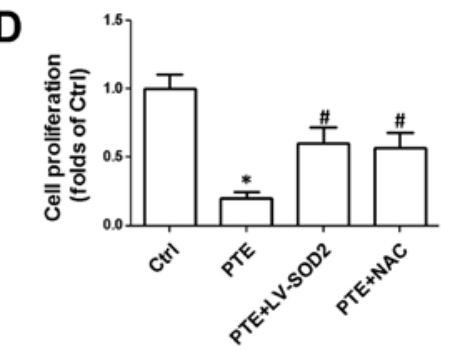

$\mathbf{F}$

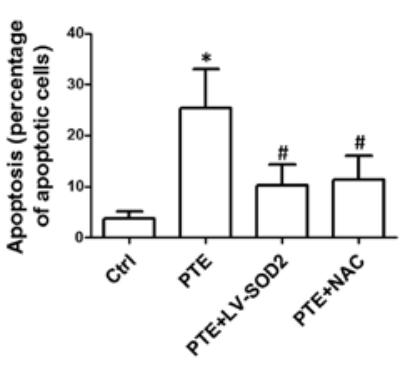

Figure 3. Role of ROS generation in the effect of PTE on cell viability, proliferation and apoptosis. DEN plus $\mathrm{CCl}_{4}$-treated mice were injected with $200 \mathrm{mg} / \mathrm{kg}$ PTE with or without $10 \mathrm{mg} / \mathrm{kg}$ PFT $\alpha$, or LV-SOD2 or NAC. HepG2 cells were transfected with scramble lentivirus or LV-SOD2 and then incubated with $100 \mu \mathrm{M}$ PTE in the presence or absence of $10 \mu \mathrm{M}$ PFT $\alpha$ or NAC for $24 \mathrm{~h}$. (A) ROS levels in liver tumor tissue and (B) HepG2 cells were determined by DHE staining and representative images are shown. (C) Cell viability was detected by an MTT assay and (D) cell proliferation was detected with a CCK-8 kit. (E) Apoptosis in liver tumor tissue and (F) HepG2 cells was determined by TUNEL assay and the results are presented as the percentage of apoptotic cells. "p $<0.05$, compared with that of the Ctrl or DEN. " $\mathrm{p}<0.05$, compared with that of the PTE group. ROS, reactive oxygen species; PTE, pterostilbene; DEN, diethylnitrosamine; $\mathrm{CCl}_{4}$, carbon tetrachloride; SOD2, superoxide dismutase 2; NAC, $N$-acetylcysteine; Ctrl, control.
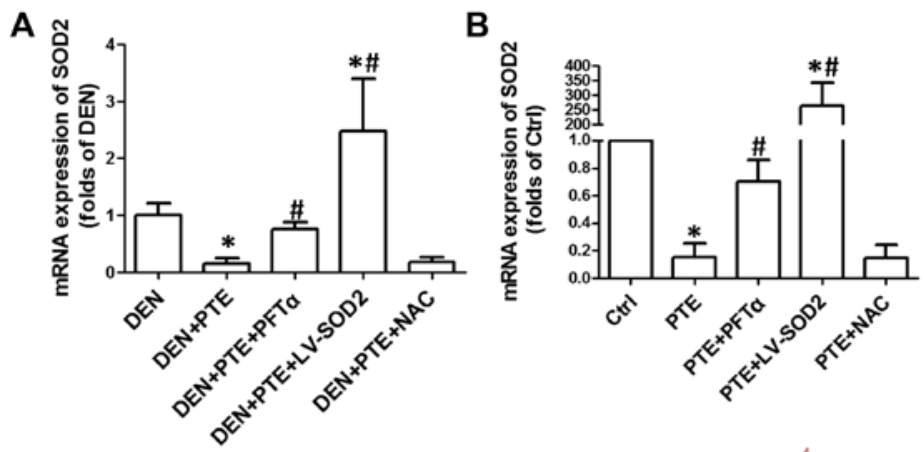

C

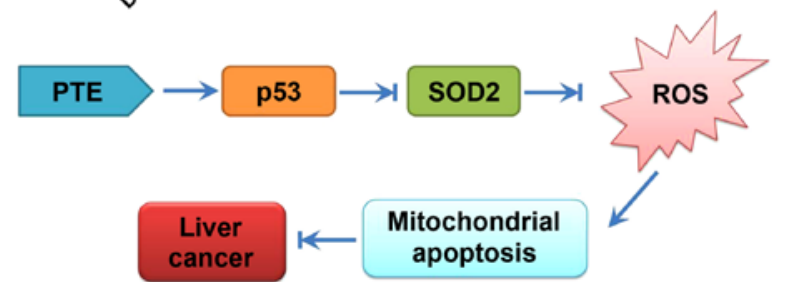

Figure 4. Role of ROS generation in the effect of PTE on cell viability, proliferation and apoptosis. DEN plus $\mathrm{CCl}_{4}$-treated mice were injected with $200 \mathrm{mg} / \mathrm{kg}$ PTE with or without $10 \mathrm{mg} / \mathrm{kg}$ PFTa, or LV-SOD2 or NAC. HepG2 cells were transfected with scramble lentivirus or LV-SOD2 and then incubated with $100 \mu \mathrm{M}$ PTE in the presence or absence of $10 \mu \mathrm{M}$ PFT $\alpha$ or NAC for $24 \mathrm{~h}$. (A) mRNA expression of SOD2 in liver tumor tissue and (B) in HepG2 cells was determined by real-time PCR and the results are presented as a fold of Ctrl. " $\mathrm{p}<0.05$, compared with that of the Ctrl or DEN. " $\mathrm{p}<0.05$, compared with that of the PTE group. (C) The molecular mechanism of the antitumor effect of PTE in HCC. ROS, reactive oxygen species; PTE, pterostilbene; DEN, diethylnitrosamine; $\mathrm{CCl}_{4}$, carbon tetrachloride; SOD2, superoxide dismutase 2; NAC, $\mathrm{N}$-acetylcysteine; HCC, hepatocellular carcinoma; Ctrl, control. 
p53 and increase in the ROS level, which activated mitochondrial apoptosis and resulted in inhibition of tumor growth and cell proliferation.

\section{Discussion}

DEN a constituent of tobacco smoke, cheddar cheese, curd and fried meals and a number of alcoholic beverages, is widely used as a hepatocarcinogenic dialkylnitrosoamine to induce an in vivo $\mathrm{HCC}$ model in its combination with $\mathrm{CCl}_{4}(20-23)$. In the present study, we investigated the inhibitory effect of PTE on tumor growth in DEN-induced HCC in mice and cancer cell proliferation in HepG2 cells. We found that PTE resulted in significant inhibition of tumor growth and cancer cell proliferation both in vivo and in vitro.

Malignant tumors are often characterized by dysregulation of apoptotic cell death $(24,25)$. Moreover, induction of apoptosis is considered to be a potent therapeutic strategy for the intervention of tumors (26-28). Numerous literature has shown that PTE has pro-apoptotic activities. Zhang et al found that PTE induced apoptosis in HeLa cells (29). Hsiao et al showed that PTE stimulated mitochondrial-derived apoptosis in human acute myeloid leukemia cell lines (30). Pan et al showed that PTE exhibited a pro-apoptotic and anti-proliferation effect in breast cancer (31). In the present study, we also examined the effect of PTE on apoptosis in vivo and in vitro. Consistently, we demonstrated that PTE exhibited pro-apoptotic effects both in liver tumor tissues of DEN-treated mice and in HCC cells, as evidenced by the increase in caspase- 3 activity and TUNEL-positive cells.

It is well-known that p53 is a tumor-suppressor gene, playing key roles in cell cycle control and induction of apoptosis through the regulation of a battery of target genes $(32,33)$. In response to death signals, activated p53 regulates various genes of pro-apoptotic proteins, which are transcription-dependent or -independent, leading to final cell death $(34,35)$. In our study, we also examined the possible role of p53 in PTE-induced regulation of apoptosis, cell proliferation and cell growth. We showed that $\mathrm{p} 53$ was responsible for PTE-induced apoptosis and inhibition of cell proliferation and tumor growth, as evidenced by PFT $\alpha$-induced suppression of the increase in apoptosis and decrease in cell proliferation and tumor growth in the PTE-treated mice and cells.

p53 is also a redox-regulating transcription factor via regulation of ROS production and the expression of various antioxidant enzymes (36). Increased ROS is believed to be able to activate the mitochondrial apoptotic pathway, resulting in cell death (37-39). In the present study, we found that PTE increased ROS generation both in vivo and in vitro through a p53-dependent manner. Moreover, PTE-induced ROS production was involved in the antitumor effect. However, previous studies have shown that PTE exhibits antioxidant activities $(40,41)$. The discrepancy is supported by the notion that the effect of PTE on the redox state may be tissue/cellspecific and concentration-dependent.

Among the antioxidant systems, SOD2 is an important member which is located in the mitochondrial matrix where it catalyzes the dismutation of a superoxide anion and plays pivotal roles in protecting against mitochondrial and intracellular ROS insult (42). In our study, we also examined the possible role of SOD2 in the inhibitory effect of PTE on tumor growth and cell proliferation. PTE resulted in a significant decrease in SOD2 expression and overexpression of SOD2 by a lentivirus inhibited PTE-induced increase in apoptosis and decrease in tumor growth and cell proliferation. The results demonstrated that downregulation of SOD2 was an essential step in the process of PTE-induced inhibition of tumor growth and HCC cell proliferation.

In the next step, we examined the sequence of upregulation of p53, downregulation of SOD2 and increase in ROS generation in response to PTE treatment. We showed that PFT $\alpha$, but not NAC, inhibited PTE-induced decrease in SOD2 expression and PFT $\alpha$, LV-SOD2 and NAC inhibited PTE-induced ROS generation, indicating that downregulation of SOD2 was required for p53-mediated ROS production induced by PTE. Previous studies found that p53-mediated downregulation of SOD2 was involved in the antitumor effect of betulinic acid in HCC (43). In combination with the results, we proposed that SOD2 may be a main target through which p53 regulates redox status and apoptosis and the p53/SOD2/ROS pathway is a common pathway that mediates the toxic effect of extracellular stimuli in HCC.

In conclusion, in the present study, we examined the effect of PTE on tumor growth in DEN-induced HCC in mice and HCC cell proliferation in HepG2 cells. The results showed that PTE inhibited tumor growth in vivo and HCC cell proliferation in vitro. PTE increased p53 expression, decreased SOD2 expression, and resulted in an increase in the ROS level and the activation of the mitochondrial apoptotic pathway, leading to inhibition of tumor growth and cell proliferation. Collectively, these data demonstrated that the p53/SOD2/ROS pathway is critical for PTE-inhibited tumor growth and HCC cell proliferation.

\section{References}

1. Ferlay J, Shin HR, Bray F, Forman D, Mathers C and Parkin DM: Estimates of worldwide burden of cancer in 2008: GLOBOCAN 2008. Int J Cancer 127: 2893-2917, 2010.

2. El-Serag HB and Rudolph KL: Hepatocellular carcinoma: Epidemiology and molecular carcinogenesis. Gastroenterology 132: 2557-2576, 2007.

3. Ferlay J, Soerjomataram I, Dikshit R, Eser S, Mathers C, Rebelo M, Parkin DM, Forman D and Bray F: Cancer incidence and mortality worldwide: Sources, methods and major patterns in GLOBOCAN 2012. Int J Cancer 136: E359-E386, 2015.

4. Yeh YP, Hu TH, Cho PY, Chen HH, Yen AM, Chen SL, Chiu SY, Fann JC, Su WW, Fang YJ, et al; Changhua Community-Based Abdominal Ultrasonography Screening Group: Evaluation of abdominal ultrasonography mass screening for hepatocellular carcinoma in Taiwan. Hepatology 59: 1840-1849, 2014.

5. Pascual S, Herrera I and Irurzun J: New advances in hepatocellular carcinoma. World J Hepatol 8: 421-438, 2016.

6. Cabibbo G, Enea M, Attanasio M, Bruix J, Craxì A and Cammà C: A meta-analysis of survival rates of untreated patients in randomized clinical trials of hepatocellular carcinoma. Hepatology 51: 1274-1283, 2010.

7. Schmidt S, Follmann M, Malek N, Manns MP and Greten TF: Critical appraisal of clinical practice guidelines for diagnosis and treatment of hepatocellular carcinoma. J Gastroenterol Hepatol 26: 1779-1786, 2011

8. Roxburgh P and Evans TR: Systemic therapy of hepatocellular carcinoma: Are we making progress? Adv Ther 25: 1089-1104, 2008.

9. Tejeda-Maldonado J, García-Juárez I, Aguirre-Valadez J, González-Aguirre A, Vilatobá-Chapa M, Armengol-Alonso A, Escobar-Penagos F, Torre A, Sánchez-Avila JF and CarrilloPérez DL: Diagnosis and treatment of hepatocellular carcinoma: An update. World J Hepatol 7: 362-376, 2015. 
10. Bruix J, Gores GJ and Mazzaferro V: Hepatocellular carcinoma: clinical frontiers and perspectives. Gut 63: 844-855, 2014.

11. Lombardi G, Vannini S, Blasi F, Marcotullio MC, Dominici L, Villarini M,CossignaniL and Moretti M: In vitro safety/protection assessment of resveratrol and pterostilbene in a human hepatoma cell line (HepG2). Nat Prod Commun 10: 1403-1408, 2015.

12. Pan MH, Chiou YS, Chen WJ, Wang JM, Badmaev V and Ho CT: Pterostilbene inhibited tumor invasion via suppressing multiple signal transduction pathways in human hepatocellular carcinoma cells. Carcinogenesis 30: 1234-1242, 2009.

13. Remsberg CM, Yáñez JA, Ohgami Y, Vega-VillaKR, Rimando AM and Davies NM: Pharmacometrics of pterostilbene: Preclinical pharmacokinetics and metabolism, anticancer, antiinflammatory, antioxidant and analgesic activity. Phytother Res 22: 169-179, 2008

14. Feng Y, Yang Y, Fan C, Di S, Hu W, Jiang S, Li T, Ma Z, Chao D, Feng $\mathrm{X}$, et al: Pterostilbene inhibits the growth of human esophageal cancer cells by regulating endoplasmic reticulum stress. Cell Physiol Biochem 38: 1226-1244, 2016.

15. Dhar S, Kumar A, Zhang L, Rimando AM, Lage JM, Lewin JR, Atfi A, Zhang X and Levenson AS: Dietary pterostilbene is a novel MTA1-targeted chemopreventive and therapeutic agent in prostate cancer. Oncotarget 7: 18469-18484, 2016.

16. Nikhil K, Sharan S and Roy P: A pterostilbene derivative suppresses osteoclastogenesis by regulating RANKL-mediated NFкB and MAPK signaling in RAW264.7 cells. Pharmacol Rep 67: 1264-1272, 2015.

17. Sun Y, Wu X, Cai X, Song M, Zheng J, Pan C, Qiu P, Zhang L, Zhou S, Tang Z, et al: Identification of pinostilbene as a major colonic metabolite of pterostilbene and its inhibitory effects on colon cancer cells. Mol Nutr Food Res 60: 1924-1932, 2016.

18. Huang CS, Ho CT, Tu SH, Pan MH, Chuang CH, Chang HW, Chang $\mathrm{CH}, \mathrm{Wu} \mathrm{CH}$ and Ho YS: Long-term ethanol exposure-induced hepatocellular carcinoma cell migration and invasion through lysyl oxidase activation are attenuated by combined treatment with pterostilbene and curcumin analogues. J Agric Food Chem 61: 4326-4335, 2013.

19. Hacker HJ, Mtiro H, Bannasch P and Vesselinovitch SD Histochemical profile of mouse hepatocellular adenomas and carcinomas induced by a single dose of diethylnitrosamine. Cancer Res 51: 1952-1958, 1991.

20. Fausto $\mathrm{N}$ and Campbell JS: Mouse models of hepatocellular carcinoma. Semin Liver Dis 30: 87-98, 2010.

21. Zhao X, Fu J, Xu A, Yu L, Zhu J, Dai R, Su B, Luo T, Li N Qin W, et al: Gankyrin drives malignant transformation of chronic liver damage-mediated fibrosis via the Rac1/JNK pathway. Cell Death Dis 6: e1751, 2015.

22. Qin XY, Tatsukawa H, Hitomi K, Shirakami Y, Ishibashi N, Shimizu M, Moriwaki $\mathrm{H}$ and Kojima S: Metabolome analyses uncovered a novel inhibitory effect of acyclic retinoid on aberrant lipogenesis in a mouse diethylnitrosamine-induced hepatic tumorigenesis model. Cancer Prev Res (Phila) 9: 205-214, 2016.

23. Shibata Y, Hara T, Nagano J, Nakamura N, Ohno T, Ninomiya S, Ito $\mathrm{H}$, Tanaka $\mathrm{T}$, Saito $\mathrm{K}$, Seishima $\mathrm{M}$, et al: The role of indoleamine 2,3-dioxygenase in diethylnitrosamine-induced liver carcinogenesis. PLoS One 11: e0146279, 2016.

24. Goldar S, Khaniani MS, Derakhshan SM and Baradaran B: Molecular mechanisms of apoptosis and roles in cancer development and treatment. Asian Pac J Cancer Prev 16: 2129-2144, 2015.

25. Kundu J, Chun KS, Aruoma OI and Kundu JK: Mechanistic perspectives on cancer chemoprevention/chemotherapeutic effects of thymoquinone. Mutat Res 768: 22-34, 2014.
26. Jiang CF, Wen LZ, Yin C, Xu WP, Shi B, Zhang X and Xie WF: Apoptosis signal-regulating kinase 1 mediates the inhibitory effect of hepatocyte nuclear factor- $4 \alpha$ on hepatocellular carcinoma. Oncotarget 7: 27408-27421, 2016.

27. Li J, Liang L, Liu Y, Luo Y, Liang X, Luo D, Feng Z, Dang Y, Yang L and Chen G: Clinicopathological significance of STAT4 in hepatocellular carcinoma and its effect on cell growth and apoptosis. Onco Targets Ther 9: 1721-1734, 2016.

28. Chen X, Tan M, Xie Z, Feng B, Zhao Z, Yang K, Hu C, Liao N, Wang T, Chen D, et al: Inhibiting ROS-STAT3-dependent autophagy enhanced capsaicin-induced apoptosis in human hepatocellular carcinoma cells. Free Radic Res 50: 744-755, 2016.

29. Zhang B, Wang XQ, Chen HY and Liu BH: Involvement of the Nrf2 pathway in the regulation of pterostilbene-induced apoptosis in HeLa cells via ER stress. J Pharmacol Sci 126: 216-229, 2014.

30. Hsiao PC, Chou YE, Tan P, Lee WJ, Yang SF, Chow JM Chen HY, Lin CH, Lee LM and Chien MH: Pterostilbene simultaneously induced G0/G1-phase arrest and MAPK-mediated mitochondrial-derived apoptosis in human acute myeloid leukemia cell lines. PLoS One 9: e105342, 2014.

31. Pan C, Hu Y, Li J, Wang Z, Huang J, Zhang S and Ding L: Estrogen receptor- $\alpha 36$ is involved in pterostilbene-induced apoptosis and anti-proliferation in in vitro and in vivo breast cancer. PLoS One 9: e104459, 2014

32. Jiang L, Kon N, Li T, Wang SJ, Su T, Hibshoosh H, Baer R and $\mathrm{Gu}$ W: Ferroptosis as a p53-mediated activity during tumour suppression. Nature 520: 57-62, 2015.

33. Nakano K and Vousden KH: PUMA, a novel proapoptotic gene, is induced by p53. Mol Cell 7: 683-694, 2001

34. Liu J, Zhang C, Hu W and Feng Z: Tumor suppressor p53 and its mutants in cancer metabolism. Cancer Lett 356: 197-203, 2015.

35. Chi SW: Structural insights into the transcription-independent apoptotic pathway of p53. BMB Rep 47: 167-172, 2014.

36. Maillet A and Pervaiz S: Redox regulation of p53, redox effectors regulated by p53: a subtle balance. Antioxid Redox Signal 16: 1285-1294, 2012

37. Wang X, Liu J, Jiang L, Wei X, Niu C, Wang R, Zhang J, Meng D, Yao K: Bach1 induces endothelial cell apoptosis and cell-cycle arrest through ROS generation. Oxid Med Cell Longev 2016: 6234043, 2016

38. Wang H, Sun N, Li X, Li K, Tian J and Li J: Diallyl trisulfide induces osteosarcoma cell apoptosis through reactive oxygen species-mediated downregulation of the PI3K/Akt pathway. Oncol Rep 35: 3648-3658, 2016.

39. Jia J, Qin Y, Zhang L, Guo C, Wang Y, Yue X and Qian J: Artemisinin inhibits gallbladder cancer cell lines through triggering cell cycle arrest and apoptosis. Mol Med Rep 13: 4461-4468, 2016.

40. Bhakkiyalakshmi E, Sireesh D, Sakthivadivel M, Sivasubramanian S, Gunasekaran P and Ramkumar KM: Anti-hyperlipidemic and antiperoxidative role of pterostilbene via Nrf 2 signaling in experimental diabetes. Eur J Pharmacol 777: 9-16, 2016.

41. Elango B, Dornadula S, Paulmurugan R and Ramkumar KM: Pterostilbene ameliorates streptozotocin-induced diabetes through enhancing antioxidant signaling pathways mediated by nrf2. Chem Res Toxicol 29: 47-57, 2016.

42. Fridovich I: Superoxide radical and superoxide dismutases. Annu Rev Biochem 64: 97-112, 1995.

43. Yang J, Qiu B, Li X,Zhang H and Liu W: p53-p66 $6^{\text {shc }} / \mathrm{miR}-21-$ Sod2 signaling is critical for the inhibitory effect of betulinic acid on hepatocellular carcinoma. Toxicol Lett 238: 1-10, 2015. 